\title{
Rheological, pasting, thermal and retrogradation properties of octenyl succinic anhydride modified potato starch
}

\author{
Chuin WON ${ }^{1}$, Yong Ik JIN², Dong-Chil CHANG², Misook KIM ${ }^{3}$, Youngseung $\mathrm{LEE}^{3}$, Palanivel GANESAN ${ }^{4}$, \\ Yun-Kyung LEE ${ }^{1}$, Yoon Hyuk CHANG ${ }^{1 *}$
}

\begin{abstract}
The objective of the present study was to investigate the rheological, pasting, and thermal properties of octenyl succinic anhydrate (OSA)-modified potato starch. Potato starch was modified using different concentrations of OSA $(0,1,3$, and $5 \%$, $\mathrm{v} / \mathrm{v}$ ). The degree of substitution (DS) for the OSA-modified starch ranged from 0.0012 to 0.0055 . The amylose leaching values of native and OSA-modified potato starch with different DS levels were in the range of $47.09-87.32 \%$. The gel strength values of the OSA-modified starch were lower than those of native potato starch. Rapid Visco Analyzer data showed that peak, hot pasting, final and setback viscosities of the native starch decreased after OSA modification. Dynamic shear rheological tests, conducted at $4{ }^{\circ} \mathrm{C}$, indicated that OSA-modified potato starch had weak gel-like behavior with the storage moduli ( $\left.\mathrm{G}^{\prime}\right)$ higher than the loss moduli $\left(G^{\prime \prime}\right)$ over most of the frequency ranges $\left(0.63-63.8 \mathrm{rad} \cdot \mathrm{s}^{-1}\right)$.
\end{abstract}

Keywords: potato starch; octenyl succinic anhydride; rheological property; pasting property; retrogradation.

Practical Application: Higher stability of OSA-modified potato starch can better withstand freeze-thawing of frozen food.

\section{Introduction}

Potato starch is a good texture stabilizer and regulator in food; however, limitations like low shear stress resistance, thermal resistance, thermal decomposition, and high retrogradation have limited its use in some industrial food applications (Hong et al., 2016). It is possible to modify the starch molecule by the introduction of a chemical modification, which can result in a starch molecule with markedly altered physicochemical properties. For example, modification of native granular starches profoundly alters their rheological, gelatinization, pasting, and retrogradation behaviors. The type of modification that can be achieved, and therefore the change in functional properties, is based on the starch source and type of substitution (Shogren et al., 2000). Starch modification can be achieved through derivatization such as esterification, etherification, cross-linking, or grafting.

Starch alkenylsuccinates, such as dodecenyl succinic anhydride, octadecenyl succinic anhydride, and octenyl succinic anhydride (OSA), are usually prepared commercially by a base-catalyzed reaction of alkenyl succinic anhydride with granular starch in aqueous suspension (Miao et al., 2014). Among the alkenyl succinic anhydrides, OSA is permitted by the US FDA to be used in foods at a level of $3 \%$ treatment [DS (degree of substitution): 0.02]. Octenylsuccinylation imparts a hydrophobic character to starch and it is known to weaken the internal bonding that holds the granules together (Bello-Flores et al., 2014).
Retrogradation is a general term for the recrystallization behavior of gelatinized starches upon cooling and storage, and is accompanied by gel hardening and the leakage of water from the starch gel (Lian et al., 2014). Retrogradation is an important issue in the use of starch as a food ingredient in processing and preservation, because, as time passes, the quality of the food's texture and physical properties deteriorate. This difficulty arises frequently in food processing because the physical and chemical properties of starch pastes change during long storage time due to retrogradation. The extent of retrogradation depends on various factors such as the type of starch, starch concentration, and temperature.

Chemical substitution of starch side chains with a succinate group leads to an inhibition of the ordered structure of starch paste, thus retarding retrogradation and resulting in a more fluid paste with improved clarity (Subaric et al., 2014; Yadav \& Patki, 2015). The freeze-thaw stability of banana starch can be improved by preventing starch chain alignment through the incorporation of hydroxypropyl groups into the starch during storage, consequently leading to decreased retrogradation (Bello-Perez et al., 2000). Furthermore, OSA modification can inhibit amylose chain interactions and reduce the formation of junction zones, resulting in the formation of a weaker gel. 
Chemical modification of starches affects the rheological properties of the final products because a small change in the molecular conformation and structure of starch can result in dramatic changes in rheological properties. Therefore, it is necessary to determine the rheological properties of chemically modified starches. This knowledge is important in understanding how the chemically modified starch affects handling, processing, mastication, and utilization of the food to which it may be added. OSA groups tend to weaken the interactions between starch macromolecules, allowing the granules to swell and to melt at lower temperatures and decrease the steady and dynamic shear rheological properties (Park et al., 2004).

A majority of the earlier studies on starch modification by OSA were performed using waxy corn starch, although recently wheat and rice have also been studied (Chung et al., 2010; Wang et al., 2015, 2016). OSA-modified potato starches have been studied with regard to preparation conditions and physicochemical properties. However, little work has been done on assessing the rheological, retrogradation, pasting, and thermal properties of OSA-modified potato starch. Therefore, the objective of the present study was to elucidate the effects of OSA modification on these properties of potato.

\section{Material and methods}

\subsection{Materials}

Potato 'Go-un' was provided by Highland Agriculture Research Institute, National institute of Crop Science (NICS), Korea. High purity OSA was purchased from Sigma-Aldrich Chemical Co. (St. Louis, MO, USA). The other chemicals used in the study were of analytical grade.

\subsection{Preparation of potato starch}

The potato sample was washed, peeled, sliced into $2-3 \mathrm{~cm}$ slices, and lyophilized in a freeze dryer (FDS8508, Ilshin Bio Base, Gyeonggi, Korea). To produce potato powder, the dried sample was ground in a blender (7011, Waring Laboratory Science, Stamford, CT, USA), passed through a $150-\mu \mathrm{m}$ sieve, and stored at $-20{ }^{\circ} \mathrm{C}$ in sealed plastic containers until further use. Potato powder $(250 \mathrm{~g})$ was cleaned, steeped in bisulfite solution (1 L) at $58^{\circ} \mathrm{C}$ for $2 \mathrm{~h}$, washed with distilled water three times, and finally centrifuged at 3,500 rpm for $10 \mathrm{~min}$ (VS-5000N, Vision Scientific Co. Ltd. Korea). After centrifugation, the protein layer was separated. The steps of centrifugation and protein layer separation were repeated until white starch was obtained. The native potato starch was dried at $40^{\circ} \mathrm{C}$ for $48 \mathrm{~h}$ and stored at $-20^{\circ} \mathrm{C}$ in sealed plastic containers until further use.

\subsection{Total starch and amylose content}

The chemical composition of native potato starch including moisture, crude ash, crude protein, and crude lipid content was determined according to AACCI Approved Methods 44-15A, 08-01, 46-13, and 920.39, respectively (American Association of Cereal Chemists International, 2000). The total starch content in native potato starch was determined based on AOAC Approved Method 996.11 (Association of Official Agricultural Chemists,
2010). The amylose content in native potato starch was determined by the iodine colorimetry method.

\subsection{Production of OSA modified potato starch}

OSA-modified potato starch samples were obtained using the modified method of Hui et al. (2009). Native potato starch (125 g) was suspended in $475 \mathrm{~mL}$ distilled water at room temperature, and the slurry was mixed with a stirrer. The $\mathrm{pH}$ of the homogeneous slurry was adjusted to $\mathrm{pH} 9.0$ by the addition of $3 \%(\mathrm{w} / \mathrm{v}) \mathrm{NaOH}$ solution. To this mixture, OSA at 1,3 , and $5 \%$ (based on starch weight) was added dropwise for $2 \mathrm{~h}$ with addition after $30 \mathrm{~min}$. During the addition of OSA, the $\mathrm{pH}$ was maintained at 9.0. The reaction was then allowed to proceed for $24 \mathrm{~h}$. At the end of reaction, the $\mathrm{pH}$ was adjusted to $6.5 \mathrm{using}$ $3 \%(\mathrm{v} / \mathrm{v}) \mathrm{HCl}$. The resulting OSA-modified potato starch was washed with distilled water and centrifuged at 3,000 rpm for $10 \mathrm{~min}$. OSA-modified starches were dried in an oven at $45^{\circ} \mathrm{C}$ for $48 \mathrm{~h}$, sieved through a $150-\mu \mathrm{m}$ sieve, and stored at $-20^{\circ} \mathrm{C}$ in sealed plastic containers until further use.

\subsection{Degree of substitution and amylose leaching}

The degree of substitution (DS) is the average number of hydroxyl groups substituted per glucose unit. The DS of OSA starch was determined by the modified method of Hui et al. (2009). Amylose leaching was determined based on the blue value method (Guzman et al., 2011).

\subsection{Gel strength}

Native and OSA-modified potato starch $(7 \mathrm{~g})$ were suspended in distilled water $(100 \mathrm{~mL})$ in an Erlenmeyer flask with a screw cap and placed in a boiling water bath at a temperature of $90^{\circ} \mathrm{C}$ for $20 \mathrm{~min}$. The hot starch pastes were poured into covered glass cylinders ( $55 \mathrm{~mm}$ diameter and $50 \mathrm{~mm}$ height), cooled at room temperature for $1 \mathrm{~h}$, and stored at $4{ }^{\circ} \mathrm{C}$ for 3 days. Gel strength was measured using a rheometer (COMPAC-100, Sun Scientific Co. Ltd, Tokyo, Japan). A cylindrical probe with a diameter of $10 \mathrm{~mm}$ was used to penetrate the gel at a speed of $1 \mathrm{~mm} \mathrm{~s}^{-1}$ for a total distance of $10 \mathrm{~mm}$. The maximum force at $10 \mathrm{~mm}$ of penetration was recorded as the gel strength $(\mathrm{g})$.

\subsection{Freeze-thaw stability}

Freeze-thaw stability was determined based on the modified method of Huang et al. (2010). Native and OSA-modified potato starch $(3 \mathrm{~g})$ were suspended in distilled water $(100 \mathrm{~mL})$ in an Erlenmeyer flask with a screw cap and placed in a boiling water bath at a temperature of $90^{\circ} \mathrm{C}$ for $20 \mathrm{~min}$. After cooling, the paste was divided into four equal parts, which were then transferred to separate centrifuge tubes. The samples were frozen at $-20^{\circ} \mathrm{C}$ for $24 \mathrm{~h}$, and then thawed at room temperature for $6 \mathrm{~h}$. One of the tubes was taken out each time and was centrifuged at 3,000 rpm for $40 \mathrm{~min}$. The water layer was decanted and the residual paste was weighed. The percentage of water separated after three freeze-thaw cycles was measured and \% Syneresis (water separated out/total weight of sample $\times 100$ ) was calculated using the following equation. 


\subsection{Pasting properties}

The pasting properties of native and OSA-modified potato starch were analyzed using a Rapid Visco Analyzer (RVA4, Newport Sci. Pty. Ltd, Warriewood, Australia). Samples were prepared by mixing starch $(2 \mathrm{~g})$ with $25 \mathrm{~mL}$ of distilled water. The mixture was stirred manually for $1 \mathrm{~min}$ to facilitate dispersion before testing. The pasting properties included the following parameters: peak viscosity (highest viscosity during heating); final viscosity (viscosity at the completion of the heating cycle); setback (final viscosity minus peak viscosity). The profile for analysis was the Standard Method according to AACCI Approved Method 76-21 (American Association of Cereal Chemists International, 2000).

\subsection{Rheological properties}

\section{Sample preparation}

OSA starch sample dispersions (3\%, w/w) were prepared by mixing starch with distilled water in an Erlenmeyer flask with a screw cap. The starch dispersion was stirred for $30 \mathrm{~min}$ at room temperature, followed by heating in a $90^{\circ} \mathrm{C}$ water bath for $30 \mathrm{~min}$ with constant mild agitation using a magnetic stirrer, in order to avoid sedimentation and agglomeration. At the end of the heating period, the hot paste was immediately transferred to the rheometer plate for the measurement of rheological properties.

\section{Steady shear rheological properties}

Steady shear rheological properties were measured at $4{ }^{\circ} \mathrm{C}$ with an MCR 102 rheometer (Anton Paar GmbH, Graz, Austria) using a parallel plate system ( $50 \mathrm{~mm}$ diameter) set at a gap of $0.5 \mathrm{~mm}$. Each sample was transferred to the rheometer plate at the desired temperature and excess material was wiped off with a spatula. Steady shear (shear stress and shear rate) data were obtained over a shear rate range of $0.01-1,000 \mathrm{~s}^{-1}$. To describe the steady shear rheological properties of the samples, the data were fitted to the well-known power law $\left(\sigma=\mathrm{K} \gamma^{\mathrm{n}}\right)$ and Casson $\left(\sigma^{0.5}=\mathrm{K}_{\mathrm{oc}}+\mathrm{Kc} \gamma^{0.5}\right)$ models. $\sigma$ is the shear stress $(\mathrm{Pa}), \gamma$ is the shear rate $\left(\mathrm{s}^{-1}\right), \mathrm{K}$ is the consistency index $\left(\mathrm{Pa} \cdot \mathrm{s}^{\mathrm{n}}\right), \mathrm{n}$ is the flow behavior index (dimensionless), and $\left(\mathrm{K}_{\mathrm{c}}\right) 2$ is the Casson plastic viscosity $\left(\eta_{\mathrm{c}}\right)$. Casson yield stress $\left(\sigma_{\mathrm{oc}}\right)$ according to the Casson model $\left(\sigma^{0.5}=\mathrm{K}_{\mathrm{oc}}+\mathrm{Kc} \gamma^{0.5}\right)$ was determined as the square of the intercept $\left(\mathrm{K}_{\mathrm{oc}}\right)$ obtained from the linear regression of the square roots of the shear rate-shear stress data. Using the magnitudes of $\mathrm{K}$ and $n$, the apparent viscosity $\left(\eta_{\mathrm{a}, 100}\right)$ at $100 \mathrm{~s}^{-1}$ was calculated.

\section{Dynamic shear rheological properties}

Dynamic shear rheological properties [storage modulus $\left(G^{\prime}\right)$, loss modulus $\left(\mathrm{G}^{\prime \prime}\right)$, complex viscosity $\left(\eta^{*}\right)$, and $\left.\tan \delta\left(\mathrm{G}^{\prime \prime} / \mathrm{G}^{\prime}\right)\right]$ of native potato starch and OSA-modified potato starch were investigated by modifying the procedure and were determined on a strain controlled Physica MCR 301 Rheometer (Anton Paar, Graz, Austria). Prior to the dynamic shear rheological measurements, a strain sweep test at a constant frequency of $0.63 \mathrm{rad} \mathrm{s}^{-1}$ determined the linear viscoelastic region. The dynamic measurements were performed at a strain value of $0.02(2 \%)$ (within the linear viscoelastic region). Frequency sweep tests of all the samples were performed using a plate/plate geometry
(50 mm diameter, $0.5 \mathrm{~mm}$ gap) at $4{ }^{\circ} \mathrm{C}$ and frequency $(\omega)$ from 0.63 to $63.8 \mathrm{rad} \mathrm{s}^{-1}$

\section{Thermal properties}

Thermal analyses of native and OSA-modified potato starch were conducted using a differential scanning calorimeter (DSC; Q200, TA Instruments, New Castle, DE, USA) equipped with a refrigerated cooling system in order to investigate the gelatinization process. Samples were weighed directly onto the aluminum DSC pans, and distilled water was added with a micropipette to make suspensions with a $20 \%$ starch concentration. Samples were hermetically sealed and allowed to stand for $1 \mathrm{~h}$ at room temperature prior to heating in the DSC. Samples were then heated from 30 to $130{ }^{\circ} \mathrm{C}$, with increments of $5^{\circ} \mathrm{C} / \mathrm{min}$. The instrument was calibrated using indium and an empty pan as reference. From the curve obtained, the onset temperature $\left(\mathrm{T}_{\mathrm{o}}\right)$, peak temperature $\left(\mathrm{T}_{\mathrm{p}}\right)$, conclusion temperature $\left(\mathrm{T}_{\mathrm{c}}\right)$, and enthalpy $(\Delta \mathrm{H})$ of the starch gelatinization were calculated using the Universal Analysis software provided by the manufacturer.

\section{Statistical analysis}

All statistical analyses were performed using SAS version 9.1 (SAS Institute Inc., Cary, NC, USA). Analysis of variance (ANOVA) was performed using the general linear models (GLM) procedure to determine significant differences among the samples. Means were compared using Fisher's least significant difference (LSD) procedure. Significance was defined at the 5\% level.

\section{Results and discussion}

\subsection{Chemical composition and degree of substitution}

The extracted starch contained $8.34 \%$ moisture, $0.61 \%$ crude protein, $0.20 \%$ crude fat, $0.27 \%$ crude ash, and $90.57 \%$ total starch. The isolated native potato starch contained $35.21 \%$ amylose with an amylopectin content of 55.36\% (data not shown).

Potato starches modified with different levels of OSA were subjected to DS analysis. The DS values of OSA-treated potato starches ranged from of 0.0012 to 0.0055 (Table 1). Increasing the OSA levels from 1 to $5 \%$ significantly increased the DS values of modified potato starch $(\mathrm{p}<0.05)$. For comparison, the DS values of 1.0, 1.5, 2.0, 2.5, and 3.0\% OSA treated waxy maize starches were reported to be $0.0062,0.0089,0.0159,0.0183$, and 0.0206, respectively (Bhosale \& Singhal, 2006). The same group also reported the DS values of amaranth starches modified with $1.0,1.5,2.0,2.5$, and $3.0 \%$ OSA to be $0.0072,0.0084,0.0165$, 0.0175 , and 0.0203 , respectively. According to the US FDA regulations, the level of OSA for starch modification is restricted to $3 \%$ (DS < 0.02 ) based on the weight of starch.

\subsection{Amylose leaching}

The extent of amylose leaching at $80^{\circ} \mathrm{C}$ for native and OSA-modified potato starches is presented in Table 1. The amylose leaching values of native and OSA-modified potato starch with different DS values (0.0012-0.0055) were in the range of 47.09-87.32\%. OSA starches had significantly lower amylose leaching values than native potato starch, and amylose leaching 
significantly decreased as the DS values increased $(p<0.05)$. Amylose leaching has been shown to be influenced by the extent of interaction between amylose chains, amylose-amylopectin chains, as well as the total amylose content. OSA treatment can prevent the chain interactions, thereby preventing amylose leaching (Song et al., 2006). Therefore, in the OSA-modified potato starch, the greater the amount of OSA used, the lower the amount of amylose leaching.

\subsection{Gel strength}

The gel strength values of OSA-modified potato starches compared to those of the native potato starch, measured at $4{ }^{\circ} \mathrm{C}$ on days 1-3, are shown in Table 1 . The gel strength values decreased with increasing DS, indicating that the OSA potato starch gels with a higher DS were less hard compared to the native potato starch. Similarly, it has been reported that the gel strength of OSA-modified rice starch decreased, and gel stability improved, after aging at $48^{\circ} \mathrm{C}$ for four and seven days (Song et al., 2006). These results could be explained by the inhibition of amylose chain interactions and reduction in formation of junction zones as a result of esterification, leading to the formation of a weaker gel (Hong et al., 2016). From these observations, it is suggested that the retrogradation of native potato starch appears to be reduced by OSA esterification.

\subsection{Freeze-thaw stability}

The effects of freeze-thawing on native and OSA starch pastes are shown in Table 1. OSA potato starches with different DS levels had lower degrees of syneresis than the native potato starch. Moreover, the freeze-thaw stability increased along with the increase in DS. During the third freeze-thaw cycle, the native potato starch gels had a spongy-like texture and exuded $76 \%$ water, while the gels from OSA starch (DS=0.0055) were soft and elastic, and discharged only $60 \%$ water. In previous reports, OSA-modified corn starch, citric acid-modified cassava starch, and acetic acid-modified oat starch also showed improved freeze- thaw stability (Wang et al., 2015). The syneresis of esterified starch pastes improved significantly during refrigerated storage. Consequently, OSA-modified potato starch could be used to stabilize starch gels under low temperature conditions that favor retrogradation. The introduction of long-chain groups, such as OSA, into the starch molecules increases spatial hindrance, thereby impeding the association between starch chains and allowing them to increase their water retention capacity under refrigerated conditions.

\subsection{Pasting properties}

The pasting properties of the native potato starch and the OSA-modified potato starches with different DS levels were studied using a Rapid Visco Analyzer (RVA) and the results are presented in Table 2. The peak viscosities of all the OSA-modified potato starches were significantly lower than those of the native potato starch $(\mathrm{p}<0.05)$. A similar trend of lower peak viscosity was found in succinyl- and acetyl-derivatives of a hybrid maize starch $(135 \mathrm{cP})$ compared to its counterpart native hybrid maize starch $(165 \mathrm{cP})$. The pasting properties of starches have been reported to be influenced by size, rigidity, amylose to amylopectin ratio, and swelling power of the granules. Peak viscosity measures the water-holding capacity of the starch in terms of the resistance of swollen granules to shear and the swelling performance of granules (Sandhu et al., 2015). The hot pasting viscosity and final viscosity of native potato starch were also observed to be decreased after OSA modification. The setback value, an index of retrogradation tendency, of the native potato starch decreased significantly after OSA treatment $(p<0.05)$. The setback value is more likely related to the retrogradation tendency of amylose leached from starch granules since the initial gel network development is dominated by amylose gelation (Huang et al., 2010). As mentioned earlier, amylose leaching of potato starch was decreased with increasing DS levels. Therefore, we suggest that the setback values of potato starch are positively correlated with the amount of amylose leached from the starch granules during gelatinization. In addition, these data confirm our previous

Table 1. Degree of substitution (DS), amylose leaching, gel strength, and syneresis for native and octenyl succinic anhydride (OSA) modified potato starches.

\begin{tabular}{ccccc}
\hline OSA content (\%) & DS & Amylose leaching (\%) & Gel strength (\%) & Syneresis $(\%)$ \\
\hline 0 (Native) & - & $87.32 \pm 0.11^{\mathrm{a}}$ & $653.38 \pm 12.68^{\mathrm{a}}$ & $76.00 \pm 0.00^{\mathrm{a}}$ \\
1 & $0.0012 \pm 0.0001^{\mathrm{c}}$ & $61.42 \pm 0.28^{\mathrm{b}}$ & $177.67 \pm 11.13^{\mathrm{b}}$ & $70.00 \pm 2.83^{\mathrm{b}}$ \\
3 & $0.0031 \pm 0.0000^{\mathrm{b}}$ & $60.43 \pm 0.17^{\mathrm{c}}$ & $121.61 \pm 0.89^{\mathrm{c}}$ & $68.00 \pm 0.00^{\mathrm{b}}$ \\
5 & $0.0055 \pm 0.0002^{\mathrm{a}}$ & $47.09 \pm 0.64^{\mathrm{d}}$ & $105.79 \pm 0.63^{\mathrm{c}}$ & $60.00 \pm 2.83^{\mathrm{c}}$ \\
\hline
\end{tabular}

a-d Values with different letters within the same column differ significantly $(p<0.05)$.

Table 2. Effect of degree of substitution (DS) on pasting properties for native and octenyl succinic anhydride (OSA) modified potato starches.

\begin{tabular}{|c|c|c|c|c|}
\hline DS & $\begin{array}{c}\text { Peak viscosity } \\
(\mathrm{RVU})^{2}\end{array}$ & $\begin{array}{c}\text { Hot paste viscosity } \\
(\mathrm{RVU})\end{array}$ & $\begin{array}{c}\text { Final viscosity } \\
\text { (RVU) }\end{array}$ & $\begin{array}{l}\text { Setback } \\
\text { (RVU) }\end{array}$ \\
\hline-1 & $4119.00 \pm 143.42^{a}$ & $3353.00 \pm 123.56^{\mathrm{a}}$ & $8150.67 \pm 45.62^{a}$ & $8150.67 \pm 45.62^{a}$ \\
\hline 0.0012 & $4093.00 \pm 2.65^{\mathrm{a}}$ & $2214.33 \pm 297.46^{b}$ & $7035.67 \pm 73.53^{\mathrm{b}}$ & $7035.67 \pm 73.53^{b}$ \\
\hline 0.0031 & $3127.22 \pm 60.34^{\mathrm{b}}$ & $2659.00 \pm 212.98^{b}$ & $6144.18 \pm 49.00^{c}$ & $6144.00 \pm 49.00^{c}$ \\
\hline 0.0055 & $2560.67 \pm 90.16^{c}$ & $1698.00 \pm 272.86^{c}$ & $4751.00 \pm 122.65^{\mathrm{d}}$ & $4751.00 \pm 122.62^{\mathrm{d}}$ \\
\hline
\end{tabular}

${ }^{\text {a-d }}$ Values with different letters within the same column differ significantly $(p<0.05)$. ${ }^{1}$ Native potato starch. ${ }^{2}$ RVU: Rapid Visco Units. 
results on decreased gel strength, and improved freeze-thaw stability after OSA treatment.

\subsection{Rheological analysis}

\section{Steady shear rheological analysis}

The flow behavior index ( $\mathrm{n}$ ) of the native and all the OSA-modified starches, which indicates the extent of shear-thinning behavior as it deviates from 1 ( $\mathrm{n}=1$ for Newtonian flow), was in the range of $0.46-0.65$ (Table 3). The observed high shear thinning behavior of all starch samples could be associated with the greater destruction of the intra- and inter-molecular bonding systems in the starch network due to shearing at higher shear rates.

The steady shear rheological data (Table 3 ) of the OSA-modified potato starch samples showed that apparent viscosity, consistency index $(K)$, and Casson yield stress $\left(\sigma_{\text {oc }}\right)$ of OSA-modified potato starch were significantly lower than those of the native potato starch and decreased significantly as the DS levels increased. This behavior has been attributed to the disintegration of weak potato starch granules due to the disruption of hydrogen bonds caused by the incorporation of OSA groups into the starch molecules (Shogren et al., 2000). Octenyl succinylation imparts a hydrophobic character to starch and it is known to weaken the internal bonding that holds the granules together. Alternatively, esterification by OSA treatment could inhibit amylose chain interactions and reduce the formation of junction zones, resulting in the formation of a weaker gel (Hong et al., 2016). Another possible reason for the reduction in $K$ and $\sigma_{\text {oc }}$ values after OSA modification could be the reduced amylose leaching during gelatinization (Table 1). Based on the results on amylose leaching, peak viscosity, and steady shear rheological properties, this indicates that the pasting and steady shear properties of OSA-modified potato starch can be affected by the amount of amylose leached from starch granules during gelatinization.

\section{Dynamic shear rheological analysis}

The changes in storage modulus $\left(G^{\prime}\right)$, loss modulus $\left(G^{\prime \prime}\right)$, and complex viscosity $\left(\eta^{*}\right)$ as a function of frequency $(\omega)$ for the native and all of the OSA-modified potato starch pastes at $4^{\circ} \mathrm{C}$ are shown in Figure 1. The magnitudes of $\mathrm{G}^{\prime}$ and $\mathrm{G}^{\prime \prime}$ increased as frequency values were increased (0.63-63.8 $\left.\mathrm{rad} \mathrm{s}^{-1}\right)$, while those of $\eta^{*}$ decreased. The magnitudes of $G^{\prime}$ were also much greater than those of $G^{\prime \prime}$ at all frequencies, indicating that all the samples exhibited rheological behaviors similar to those of strong gels.

Table 4 lists $\mathrm{G}^{\prime}, \mathrm{G}^{\prime \prime}$, and $\eta^{\star}$ values at $6.28 \mathrm{rad} \mathrm{s}^{-1}$ for native and all OSA potato starch pastes at $4^{\circ} \mathrm{C}$. The dynamic moduli $\left(G^{\prime}, G^{\prime \prime}\right)$ and $\eta^{\star}$ values of all OSA potato starch pastes were significantly lower than those of the native potato starch. The lowered dynamic moduli observed for OSA potato starch might be explained by the OSA groups that cause weaker granular integrity, leading to greater water uptake into the swollen granules of the potato starch paste (Thirathumthavorn \& Charoenrein, 2006). Additionally, the decrease in dynamic moduli (G), G") and $\eta^{*}$ values with increasing DS levels might be explained by a decrease in associative forces within the potato starch granules due to esterification.

The $\tan \delta$ (ratio of $\mathrm{G}^{\prime \prime} / \mathrm{G}^{\prime}$ ) values of all samples were within the range of 0.47-0.77 (Table 4), indicating that all samples were more elastic than viscous, which is in good agreement with results found in waxy corn starch (Krstonošić et al., 2011). The OSA potato starch pastes were more viscous than the native potato starch paste, as evidenced by their higher tan $\delta$ values. These observations suggest that the viscous properties of potato starch pastes are affected by the presence of OSA groups and that they depend on the DS. Thus, the above results

Table 3. Effect of degree of substitution (DS) on apparent viscosity $\left(\eta_{\mathrm{a}, 100}\right)$, consistency index $(K)$, flow behavior index $(n)$, and casson yield stress $\left(\sigma_{o c}\right)$ values for native and octenyl succinic anhydride (OSA) modified potato starches at $4{ }^{\circ} \mathrm{C}$.

\begin{tabular}{ccccc}
\hline DS & $\begin{array}{c}\text { Apparent viscosity } \\
\eta_{\mathrm{a}, 100}(\mathrm{~Pa} \cdot \mathrm{s})\end{array}$ & $\begin{array}{c}\text { Consistency index } \\
\left(\mathrm{Pa} \cdot \mathrm{s}^{\mathrm{n}}\right)\end{array}$ & $\begin{array}{c}\text { Flow behavior index } \\
n(-)\end{array}$ & $\begin{array}{c}\text { Casson yield stress } \sigma_{\text {oc }} \\
(\mathrm{Pa})\end{array}$ \\
\hline$-^{1}$ & $4.07 \pm 0.06^{\mathrm{a}}$ & $48.72 \pm 0.47^{\mathrm{a}}$ & $0.46 \pm 0.01^{\mathrm{b}}$ & $385.16 \pm 29.05^{\mathrm{a}}$ \\
0.0012 & $2.62 \pm 0.01^{\mathrm{b}}$ & $27.14 \pm 2.09^{\mathrm{b}}$ & $0.49 \pm 0.02^{\mathrm{b}}$ & $93.82 \pm 4.09^{\mathrm{b}}$ \\
0.0031 & $2.52 \pm 0.18^{\mathrm{b}}$ & $28.22 \pm 0.78^{\mathrm{b}}$ & $0.48 \pm 0.02^{\mathrm{b}}$ & $66.58 \pm 0.08^{\mathrm{bc}}$ \\
0.0055 & $1.05 \pm 0.08^{\mathrm{c}}$ & $5.42 \pm 0.95^{\mathrm{c}}$ & $0.65 \pm 0.02^{\mathrm{a}}$ & $35.26 \pm 1.89^{\mathrm{c}}$ \\
\hline
\end{tabular}

${ }^{a-c}$ Values with different letters within the same column differ significantly $(p<0.05)$. ${ }^{1}$ Native potato starch.

Table 4. Effects of degree of substitution (DS) on storage modulus (G'), loss modulus (G'), complex viscosity $\left(\eta^{*}\right)$, and tan $\delta$ at $6.28 \mathrm{rad} / \mathrm{sec}$ for native and octenyl succinic anhydride (OSA) modified potato starch at $4{ }^{\circ} \mathrm{C}$.

\begin{tabular}{crrrr}
\hline DS & \multicolumn{1}{c}{$\mathrm{G}^{\prime}(\mathrm{Pa})$} & \multicolumn{1}{c}{$\mathrm{G}^{\prime \prime}(\mathrm{Pa})$} & $\eta^{*}(\mathrm{~Pa} \cdot \mathrm{s})$ & $\tan \delta$ \\
\hline$-^{1}$ & $21.97 \pm 1.12^{\mathrm{a}}$ & $10.54 \pm 0.43^{\mathrm{a}}$ & $3.95 \pm 0.17^{\mathrm{a}}$ & $0.47 \pm 0.00^{\mathrm{d}}$ \\
0.0012 & $16.00 \pm 1.19^{\mathrm{b}}$ & $9.69 \pm 0.30^{\mathrm{b}}$ & $2.89 \pm 0.05^{\mathrm{b}}$ & $0.62 \pm 0.02^{\mathrm{c}}$ \\
0.0031 & $5.96 \pm 0.27^{\mathrm{c}}$ & $4.23 \pm 0.01^{\mathrm{c}}$ & $1.18 \pm 0.02^{\mathrm{c}}$ & $0.70 \pm 0.02^{\mathrm{b}}$ \\
0.0055 & $5.23 \pm 0.20^{\mathrm{c}}$ & $3.98 \pm 0.00^{\mathrm{c}}$ & $1.03 \pm 0.01^{\mathrm{c}}$ & $0.77 \pm 0.03^{\mathrm{a}}$ \\
\hline
\end{tabular}

${ }^{\mathrm{a}-\mathrm{d}}$ Values with different letters within the same column differ significantly $(p<0.05) .{ }^{1}$ Native potato starch. 
indicate that the viscous properties of potato starch paste can be increased by esterification and that the extent of the increase depends on the DS.

\section{Thermal properties}

In general, thermal properties of starch are defined by the three following temperatures: $\mathrm{T}_{0}$ (the onset temperature at which the gelatinization starts), $T_{p}$ (the peak temperature that represents the endothermic peak on the DSC thermogram), and $\mathrm{T}_{c}$ (the conclusion temperature at which the sample is fully gelatinized). Table 5 presents gelatinization temperatures and enthalpies $(\Delta \mathrm{H})$ of native and OSA-modified potato starches. The $\mathrm{T}_{\mathrm{o}}, \mathrm{T}_{\mathrm{p}}$, and $\mathrm{T}_{\mathrm{c}}$ values of OSA-modified potato starches were not significantly different from those of the native starch. However, the gelatinization enthalpy $(7.93 \mathrm{~J} / \mathrm{g})$ of the modified starch with a DS level of 0.0055 was significantly lower than that of the native starch $(10.68 \mathrm{~J} / \mathrm{g})$, indicating that OSA-modified starch granules at a DS level of 0.0055 require less energy to melt. The lower enthalpy is probably explained by the weakening of hydrogen bonding by the hydrophobic alkenyl groups, which
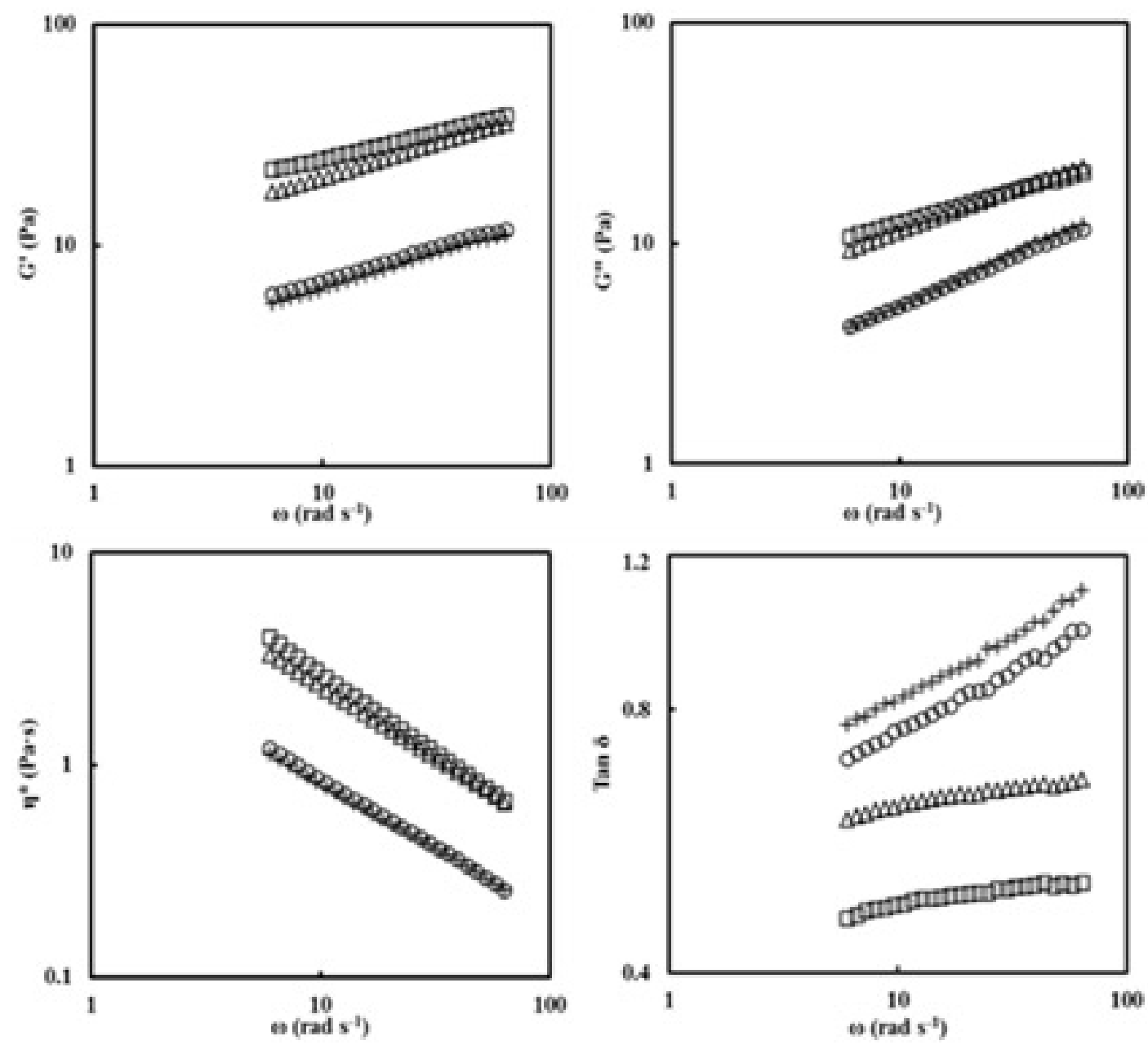

Figure 1. Plot of $\log \mathrm{g}^{\prime}, \log \mathrm{g}^{\prime \prime}$, and $\log \tan \delta$ versus $\log \omega$ (frequency, rad $\mathrm{s}^{-1}$ ) for native and octenyl succinic anhydride (OSA) modified potato starches with different degree of substitution at $4^{\circ} \mathrm{c}: 0(\square), 0.0012(\Delta), 0.0031(\circ)$, and $0.0055(+)$.

Table 5. Effect of degree of substitution (DS) on dsc gelatinization parameters for native and octenyl succinic anhydride (OSA) modified potato starches.

\begin{tabular}{ccccc}
\hline DS & $\begin{array}{c}\text { Onset } \\
\text { temperature } \\
\left({ }^{\circ} \mathrm{C}\right)\end{array}$ & $\begin{array}{c}\text { Peak } \\
\text { temperature } \\
\left({ }^{\circ} \mathrm{C}\right)\end{array}$ & $\begin{array}{c}\text { Conclusion } \\
\text { temperature } \\
\left({ }^{\circ} \mathrm{C}\right)\end{array}$ & $\begin{array}{c}\text { Enthalpy } \\
(\mathrm{g} \text { dry starch })\end{array}$ \\
\hline$-^{1}$ & $64.07 \pm 0.11^{\mathrm{ab}}$ & $67.96 \pm 0.02^{\mathrm{a}}$ & $72.45 \pm 0.17^{\mathrm{a}}$ & $10.68 \pm 0.05^{\mathrm{a}}$ \\
0.0012 & $64.62 \pm 0.23^{\mathrm{a}}$ & $67.63 \pm 0.27^{\mathrm{a}}$ & $71.58 \pm 0.01^{\mathrm{a}}$ & $10.49 \pm 0.72^{\mathrm{a}}$ \\
0.0031 & $64.33 \pm 0.17^{\mathrm{a}}$ & $67.35 \pm 0.20^{\mathrm{a}}$ & $71.53 \pm 0.54^{\mathrm{a}}$ & $10.84 \pm 0.49^{\mathrm{a}}$ \\
0.0055 & $64.43 \pm 0.01^{\mathrm{a}}$ & $67.51 \pm 0.06^{\mathrm{a}}$ & $71.36 \pm 0.01^{\mathrm{a}}$ & $7.93 \pm 0.07^{\mathrm{b}}$ \\
\hline
\end{tabular}

${ }_{\mathrm{a}, \mathrm{b}}$ Values with different letters within the same column differ significantly $(p<0.05) .{ }^{1}$ Native potato starch. 
enhances starch swelling at a relatively low temperature, thereby leading to a gradual decrease in the enthalpy of OSA starches (Thirathumthavorn \& Charoenrein, 2006).

\section{Conclusions}

In conclusion, the retrogradation property and freeze-thaw stability of potato starch were both remarkably enhanced by OSA modification. The consistency index $(K)$, apparent viscosity $\left(\eta_{a_{1100}}\right)$, and yield stress $\left(\sigma_{\mathrm{oc}}\right)$ values for potato starch were decreased as the DS levels increased, these effects are probably caused by a decrease in the interaction of amylose chains in the starch matrix during heating. Therefore, an OSA-modified potato starch with excellent gel texture and improved freeze-thaw stability could be useful in the food industry.

\section{Acknowledgements}

This work was carried out with the support of "Cooperative Research Program for Agriculture Science \& Technology Development (Project No. PJ011239032016)" Rural Development Administration, Republic of Korea.

\section{References}

American Association of Cereal Chemists International - AACC. (2000). International approved methods (11th ed.). St. Paul: AACC.

Association of Official Agricultural Chemists - AOAC. (2010). International approved methods (1094 p.). Washington: AOAC.

Bello-Flores, C. A., Nuñez-Santiago, M. C., Martín-Gonzalez, M. F. S., BeMiller, J. N., \& Bello-Pérez, L. A. (2014). Preparation and characterization of octenylsuccinylated plantain starch. International Journal of Biological Macromolecules, 70, 334-339. PMid:25036604. http://dx.doi.org/10.1016/j.ijbiomac.2014.06.061.

Bello-Perez, L. A., Contreras-Ramos, S. M., Jimenez-Aparicio, A., \& Paredes-Lopez, O. (2000). Acetylation and characterization of banana (Musa paradisiaca) starch. Acta Cientifica Venezolana, 51(3), 143-149. PMid:11265448.

Bhosale, R., \& Singhal, R. (2006). Process optimization for the synthesis of octenyl succinyl derivative of waxy corn and amaranth starches. Carbohydrate Polymers, 66(4), 521-527. http://dx.doi.org/10.1016/j. carbpol.2006.04.007.

Chung, H. J., Lee, S. E., Han, J. A., \& Lim, S. T. (2010). Physical properties of dry-heated octenyl succinylated waxy corn starches and its application in fat-reduced muffin. Journal of Cereal Science, 52(3), 496-501. http://dx.doi.org/10.1016/j.jcs.2010.08.008.

Guzman, C., Caballero, L., Alvarez, J. B., \& Yamamori, M. (2011). Amylose content and starch properties in emmer and durum wheat lines with different waxy proteins composition. Journal of the Science of Food and Agriculture, 91(9), 1625-1629. PMid:21445866. http:// dx.doi.org/10.1002/jsfa.4358.

Hong, J., Chen, R., Zeng, X. A., \& Han, Z. (2016). Effect of pulsed electric fields assisted acetylation on morphological, structural and functional characteristics of potato starch. Food Chemistry, 192, 15-24. PMid:26304315. http://dx.doi.org/10.1016/j.foodchem.2015.06.058.

Huang, Q., Fu, X., He, X. W., Luo, F. X., Yu, S. J., \& Li, L. (2010). The effect of enzymatic pretreatments on subsequent octenyl succinic anhydride modifications of cornstarch. Food Hydrocolloids, 24(1), 60-65. http://dx.doi.org/10.1016/j.foodhyd.2009.08.005.

Hui, R., Qi-He, C., Ming-Liang, F., Qiong, X., \& Guo-Qing, H. (2009). Preparation and properties of octenyl succinic anhydride modified potato starch. Food Chemistry, 114(1), 81-86. http://dx.doi.org/10.1016/j. foodchem.2008.09.019.

Krstonošić, V., Dokić, L., \& Milanović, J. (2011). Micellar properties of OSA starch and interaction with xanthan gum in aqueous solution. Food Hydrocolloids, 25(3), 361-367. http://dx.doi.org/10.1016/j. foodhyd.2010.06.014.

Lian, X., Wang, C., Zhang, K., \& Li, L. (2014). The retrogradation properties of glutinous rice and buckwheat starches as observed with FT-IR, 13C NMR and DSC. International Journal of Biological Macromolecules, 64, 288-293. PMid:24360894. http://dx.doi. org/10.1016/j.ijbiomac.2013.12.014

Miao, M., Li, R., Jiang, B., Cui, S. W., Zhang, T., \& Jin, Z. (2014). Structure and physicochemical properties of octenyl succinic esters of sugary maize soluble starch and waxy maize starch. Food Chemistry, 151, 154-160. PMid:24423515. http://dx.doi.org/10.1016/j. foodchem.2013.11.043.

Park, S., Chung, M. G., \& Yoo, B. (2004). Effect of octenylsuccinylation on rheological properties of corn starch pastes. Stärke, 56(9), 399406. http://dx.doi.org/10.1002/star.200300274.

Sandhu, K. S., Sharma, L., \& Kaur, M. (2015). Effect of granule size on physicochemical, morphological, thermal and pasting properties of native and 2-octenyl-1-ylsuccinylated potato starch prepared by dry heating under different $\mathrm{pH}$ conditions. LWT-Food Science and Technology., 61(1), 224-230. http://dx.doi.org/10.1016/j.lwt.2014.11.004.

Shogren, R. L., Viswanathan, A., Felker, F., \& Gross, R. A. (2000). Distribution of octenyl succinate groups in octenyl succinic anhydride modified waxy maize starch. Stärke, 52(6-7), 196-204. http://dx.doi.org/10.1002/1521-379X(200007)52:6/7<196::AIDSTAR196>3.0.CO;2-4.

Song, X., He, G., Ruan, H., \& Chen, Q. (2006). Preparation and Properties of Octenyl Succinic Anhydride Modified EarlyIndica Rice Starch. Stärke, 58(2), 109-117. http://dx.doi.org/10.1002/star.200500444.

Subaric, D., Ackar, D., Babic, J., Sakac, N., \& Jozinovic, A. (2014). Modification of wheat starch with succinic acid/acetic anhydride and azelaic acid/acetic anhydride mixtures I. Thermophysical and pasting properties. Journal of Food Science and Technology, 51(10), 2616-2623. PMid:25328203. http://dx.doi.org/10.1007/s13197012-0790-0.

Thirathumthavorn, D., \& Charoenrein, S. (2006). Thermal and pasting properties of native and acid-treated starches derivatized by 1-octenyl succinic anhydride. Carbohydrate Polymers, 66(2), 258-265. http:// dx.doi.org/10.1016/j.carbpol.2006.03.016.

Wang, C., He, X., Fu, X., Huang, Q., \& Zhang, B. (2016). Substituent distribution changes the pasting and emulsion properties of octenylsuccinate starch. Carbohydrate Polymers, 135, 64-71. PMid:26453852. http://dx.doi.org/10.1016/j.carbpol.2015.08.044.

Wang, C., He, X., Fu, X., Luo, F., \& Huang, Q. (2015). High-speed shear effect on properties and octenylsuccinic anhydride modification of corn starch. Food Hydrocolloids, 44, 32-39. http://dx.doi.org/10.1016/j. foodhyd.2014.09.007.

Yadav, D. K., \& Patki, P. E. (2015). Effect of acetyl esterification on physicochemical properties of chick pea (Cicer arietinum L.) starch. Journal of Food Science and Technology, 52(7), 4176-4185. PMid:26139882. http://dx.doi.org/10.1007/s13197-014-1388-5. 